\title{
Accounting Lean Management Model Based on Big Data
}

\author{
Baowei Zhang ${ }^{1 *}$ \\ ${ }^{1}$ Hainan University, Hainan, China
}

\begin{abstract}
In the environment of slowing down world economic development, the uncoordinated extensive production and industrial policies in China in the past caused the imbalance of economic supply in China. In this paper, through the use of literature analysis, comparative analysis and case analysis, taking 1 manufacturing enterprise as a case, through the analysis of enterprise production mode and cost management mode, through the construction of lean accounting cost management framework, the cost management of 1 enterprise is studied from four aspects. Through the analysis, it can be seen that the non productive resources of employees account for $36.37 \%$, of which the rework time accounts for $61.05 \%$, and the handling time accounts for $23.26 \%$. Compared with the traditional cost management, lean accounting is more suitable for the management of lean enterprises. Finally, the lean management of the enterprise is predicted.
\end{abstract}

\section{Introduction}

With the advent of the market-oriented wave, the industry competition is becoming more and more fierce, and the role of modern science and technology in promoting industry is becoming more and more obvious. There will be pressure if there is competition, and pressure will promote the growth of enterprises. In the competition, enterprises constantly realize that the original laborintensive production mode is no longer suitable for the new trend of current economic and social development. Therefore, there is a trend of transformation from domestic industries to technology intensive enterprises, and enterprises are eager for a scientific and feasible modern management scheme [1].

Economic development has promoted the improvement of people's living standards. At the same time, information globalization has given customers more choices, making customers play a leading role in the economic business with enterprises. Customers' choice of products is becoming more and more diversified and personalized. Every customer hopes to get the products they want most in the shortest time. Therefore, with the promotion of this demand, the large-scale production of enterprises no longer has advantages. In a sense, customers have the right to decide the price, so enterprises can only achieve profits by reducing costs. On the one hand, cost reduction can help enterprises to maintain competitiveness, on the other hand, enterprises should pay attention to market dynamics while reducing costs, and customers are often more familiar with the market than enterprises, which urges enterprises to take customer needs into consideration when making cost analysis. If enterprises want to maintain long-term cooperative relationship with customers, they must ensure product quality and achieve the goal Cost control and meet the needs of customers win-win purpose. In such an economic environment, many small and medium-sized enterprises have also started the reform of lean production. However, although some enterprises use lean production, they still use traditional cost management methods, and do not introduce lean thinking into accounting management [2]. Although enterprises use lean production, it does not reduce the cost consumption. The reason is that the cost management under the traditional accounting does not meet the requirements of lean, and there is no accounting analysis of the cost before and after production. Therefore, the role of lean management appears. Based on the literature at home and abroad, foreign scholars first put forward the idea of lean, and carried out research and development on lean management. In practice, Geng Wei is also very popular. He has rich experience in lean production and lean management. And many enterprises have achieved great success because of the infiltration of lean thinking. However, the lean management research in China is more imitated through the research of foreign successful enterprises, which is mostly used in automobile manufacturing enterprises. However, most of the small and medium-sized enterprises in China are not in touch with the concept of lean thinking, lack of the theory and experience of lean management practice. And this also shows that the research on the application of lean management in small and medium-sized enterprises has important practical value [3].

This paper attempts to solve the problem that the existing production mode and management mode do not match by establishing the lean cost management framework of L manufacturing enterprise. First of all, this paper analyzes the cost management methods currently adopted by 1 enterprise, and according to the current situation and combined with the lean thought, leads to the lean management cost management mode, and designs the implementation methods and results through cases. 


\section{Related Concepts}

\subsection{Accounting Lean Management}

Lean management takes lean thinking as the basic principle, through the use of value stream management method, to eliminate the waste phenomenon of enterprises and realize the maximum value of enterprises. The idea of lean management is to manage the whole input and output of the product according to the way of value stream. Cost accounting is also based on the value stream. There is no need to allocate the indirect expenses according to a certain standard. At the same time, in this process, it helps the enterprise to eliminate the part that can not bring value, that is, to avoid the transaction that does not add value. Therefore, value flow is the cost object of lean management accounting and management, and "value flow" mainly includes real logistics, capital flow and information flow. And lean management to JIT production, value stream management method, constraint theory method, six sigma method and activity management method, provides a theoretical framework for enterprises to use lean management [4].

\subsection{Lean Cost Management Concept}

Lean cost management is to implement the lean thinking into the whole process of cost management activities, through the collection of accounting information related to lean cost management, the use of final accounts and other ways of enterprise management. The content framework of lean cost management is the same as that of traditional cost management, which includes final account, accounting, analysis and assessment of cost.

Taking inventory cost decision-making as an example, this decision-making method plays a crucial role in improving enterprise profits, and JIT inventory cost decision-making method can bring more space for enterprise profits. Therefore, compared with traditional inventory decision-making method, JIT inventory cost decision-making method is more suitable for lean enterprise inventory cost management [5].

Generally speaking, cost accounting is a cost calculation method that enterprises register and collect the expenses incurred in their daily business activities, and allocate them to the corresponding product cost according to a certain standard at the end of the month. In lean cost management, cost accounting calculates the total cost of bid value stream and unit cost of each product by establishing value stream and collecting corresponding value stream cost.

Cost analysis is based on a complete set of lean cost management information platform. Through these cost information to analyze the changes of enterprise cost. Compare the actual cost with the cost forecast data, check the results of cost implementation, trace the root of cost changes, find the factors that affect the cost, and find solutions. At the same time, pre analysis of cost analysis is helpful for enterprises to make correct cost decisions, and post analysis of cost can help enterprises to improve and adjust cost management in time, summarize cost management experience and lessons, and lay the foundation for improving cost management level [6].

Cost assessment is to assess employees and lean production through lean performance indicators. Through the index assessment to understand the work of employees and the implementation of lean production. On the one hand, it can help employees improve their work enthusiasm and work together to achieve the strategic objectives of the enterprise; on the other hand, it can help enterprise managers understand the problems existing in the implementation process of lean production and quickly formulate corresponding solutions [7].

\subsection{Objectives of Lean Cost Management}

There are two main objectives of lean cost management: one is to provide more accurate and reasonable cost information, the other is to control the cost in the production process.

The main purpose of providing more accurate and reasonable cost information is to provide decision-makers with effective decision-making information, understand the profitability of enterprises through accounting profits, and the inventory also needs this cost information when preparing the balance sheet. Cost information is not only used to judge the status of enterprise assets and profitability, but also plays an important role in the production, operation and management of enterprises. Internal managers need accurate cost information to assess employees and equipment, and formulate effective cost management strategies through the analysis of cost information [8].

The purpose of cost control is to help enterprises complete manufacturing within the predetermined cost index. The main control method is to improve the work efficiency of employees and equipment and eliminate the waste in the production process. For enterprises that implement cost leadership strategy, their main goal is to save cost and improve profitability as much as possible while maintaining the same quality of products and services. For enterprises that implement differentiated cost strategy, the main goal is to complete cost management by controlling the life cycle cost of the product or service. There are different cost management methods for different life cycles. The specific cost differences mainly come from $\mathrm{R} \& \mathrm{D}$ costs, production costs, transportation costs, etc. The goal of lean cost management is to eliminate all the waste in the value stream, without creating higher value for customers to complete customer needs, so the implementation of lean cost management is more suitable for enterprises implementing differentiated cost strategy [9].

\subsection{Big Data and Its Characteristics}

(1) The origin of big data

The biggest change in the era of big data is the significant growth of data volume. With the improvement of informatization in all walks of life, all kinds of business data are exploding in the form of geometric progression. Some information can be found in the relational database, 
some data exist in the form of e-mail, word processing files and a large number of information saved and published on the Internet, as well as information found in rich video, image and sound files. In the face of data with various forms and complex contents, it is no longer possible to analyze and process it in the past. Advanced analysis tools are needed to create or utilize a structure that is easier for people to perceive and interact with, so the concept of big data emerges as the times require. Generally speaking, big data is not a simple single data, but a data set with its own characteristics. It can also be regarded as an advanced technology that can collect, sort out and analyze complex data. The ultimate value of big data lies in using new technologies to obtain useful information from massive data, analyze and predict the future, and solve existing problems in time.

(2) Big data features

Each era has its own unique characteristics, which are different from other eras. The era of big data also shows its unique characteristics. A large number of complex and diverse information shows the obvious advantages of the era of big data. Relying on the huge amount of data alone can not comprehensively summarize the uniqueness of the era of big data. Therefore, a complete grasp of the characteristics of the era of big data plays a positive role in a comprehensive understanding of the era of big data and subsequent content writing.

In the case of limited data analysis technology, people use a small amount of data to get more information, but only a small amount of data analysis can not get some micro details. When we are faced with massive data and are no longer limited by information processing capacity, it is meaningless to only analyze the sample data. In the era of big data, more attention is paid to the comprehensiveness of data, and rich and comprehensive data resources lay the foundation for reasonable analysis of data and discovery of more valuable information. More chaos refers to the pursuit of data hybridity in the era of big data. In the period of lack of information, each data information affects the results of data analysis, so only to ensure the accuracy of each data can ensure the correctness of the analysis results. Therefore, we can know that accuracy is the product of the era of lack of information. In the new era of data and network, we should correctly understand the advantages and disadvantages of accuracy. In the era of big data, all available data can be effectively used. When the amount of data is gradually increasing, the requirements for data accuracy are not so high. Accurate results can also be obtained by analyzing a large number of data. Relevance refers to the shift from focusing on causality to focusing on correlation, which is a fundamental change brought about by big data. In the past, people only pay attention to causality, but with a large amount of data, we will observe many specious correlations, and more advanced data processing tools are more conducive to find correlations. Therefore, in the era of big data, it is not necessary to grasp the causality behind the data, but the correlation between the data is enough [10].

\subsection{Basic Algorithm of Big Data:}

Mean square error

$$
R M S E=\sqrt{\frac{\sum_{(u, i) \in T}\left(r_{u i}-r_{u i}^{\prime}\right)^{2}}{|T|}}
$$

Mean absolute error

$$
M A E=\frac{\sum_{(\mathrm{u}, i) \in T}\left|r_{u i}-r_{u i}{ }^{\prime}\right|}{T}
$$

Accuracy

$$
\text { Precision }=\frac{\sum_{u \in U}|R(u) \cap T(u)|}{\sum_{u \in U}|R(u)|}
$$

\section{Construction of Accounting Lean Cost Management Based on Big Data}

\subsection{Practice Background}

L bearing manufacturing enterprise was founded in 2003, and now has more than 70 employees, including about 10 senior employees, with high bearing manufacturing technology and working experience. The production workshop of the enterprise has about 50 sets of abrasive equipment, such as processing equipment, grinding equipment and testing equipment. It can independently produce all kinds of bearings. It is a small and mediumsized enterprise with initial scale. The income of major products of 1 enterprise in recent years. Deep groove ball bearings account for about $30 \%$ of sales; self-aligning ball bearings account for about 20\%; roller bearings have increased from $22 \%$ in 14 years to $29 \%$ in 18 years, with a significant increase; linear bearings have been below $10 \%$; sales of combination bearings have decreased in recent years compared with other products, accounting for only $13 \%$ of sales in 18 years. It can be seen that the deep groove ball bearings and roller bearings of 1 enterprise have made significant progress in the market expansion in recent years.

\subsection{Confirm Enterprise Value Stream}

There are five main products on sale in 1 enterprise. Except for the combination bearing, the number of other products are basically the same. But through further understanding, we know that there are not many products that really meet the needs of lean accounting. Because the implementation of product standardization in 1 enterprise is not comprehensive, the production management of deep groove ball bearing and self-aligning ball bearing is chaotic, the task allocation of workers in charge of processing in the production line is relatively random, and there is no fixed number of product processing for the two products. Relatively speaking, the number of workers in the production line of roller bearing, linear bearing and combined bearing is relatively fixed, but because the production process of combined bearing is too short, the 
average output of linear bearing is low, which is not representative. Therefore, it is most appropriate to choose roller bearing as the main value stream of 1 enterprise for this case analysis.

\section{Statistical Analysis Results}

\subsection{Statistical Calculation and Analysis of Value Stream Cost Data}

Table1. L Enterprise Value Flow Cost Table

\begin{tabular}{|c|c|c|c|c|c|}
\hline & $\begin{array}{c}\text { Cost of } \\
\text { material }\end{array}$ & $\begin{array}{c}\text { Cost } \\
\text { of } \\
\text { labor }\end{array}$ & $\begin{array}{c}\text { Machine } \\
\text { cost }\end{array}$ & $\begin{array}{c}\text { Other } \\
\text { costs }\end{array}$ & $\begin{array}{c}\text { Total } \\
\text { cost }\end{array}$ \\
\hline Sales & & 4125 & & 265 & 4390 \\
\hline Purchase & & 2500 & & 361 & 2861 \\
\hline Machining & 34333.2 & 3240 & 937.74 & & 38510.94 \\
\hline $\begin{array}{c}\text { Heat } \\
\text { treatment }\end{array}$ & & 3760 & 1875.49 & & 5635.49 \\
\hline $\begin{array}{c}\text { Abrasive } \\
\text { machining }\end{array}$ & & 3980 & 937.74 & & 4917.74 \\
\hline
\end{tabular}

\begin{tabular}{|c|c|c|c|c|c|}
\hline $\begin{array}{c}\text { fat } \\
\text { liquoring }\end{array}$ & & 2060 & 468.87 & & 2528.87 \\
\hline $\begin{array}{c}\text { Degenerate } \\
\text { anti-rust }\end{array}$ & & 2160 & 468.87 & & 2628.87 \\
\hline $\begin{array}{c}\text { Testing } \\
\text { assembly }\end{array}$ & & 3550 & 468.87 & & 4018.87 \\
\hline $\begin{array}{c}\text { After-sale } \\
\text { service }\end{array}$ & & 2000 & & 1278 & 3278 \\
\hline Grand total & 34333.2 & 27375 & 5157.79 & 1904 & 68769.79 \\
\hline
\end{tabular}

According to the order quantity of roller bearings this month, the production plan of roller bearings this week is 1445 pieces. Its standardized operation center is divided into: sales, procurement, turning, heat treatment, grinding, oiling, demagnetization and rust prevention, testing and assembly and after-sales service. The required resource costs are: raw material costs, labor costs, equipment costs and other costs. As shown in Table 1, due to the use of standardized production, all costs can be directly obtained. The total value stream cost of circumferential roller bearing is 68769.79 yuan, and the unit cost is 47.60 yuan.

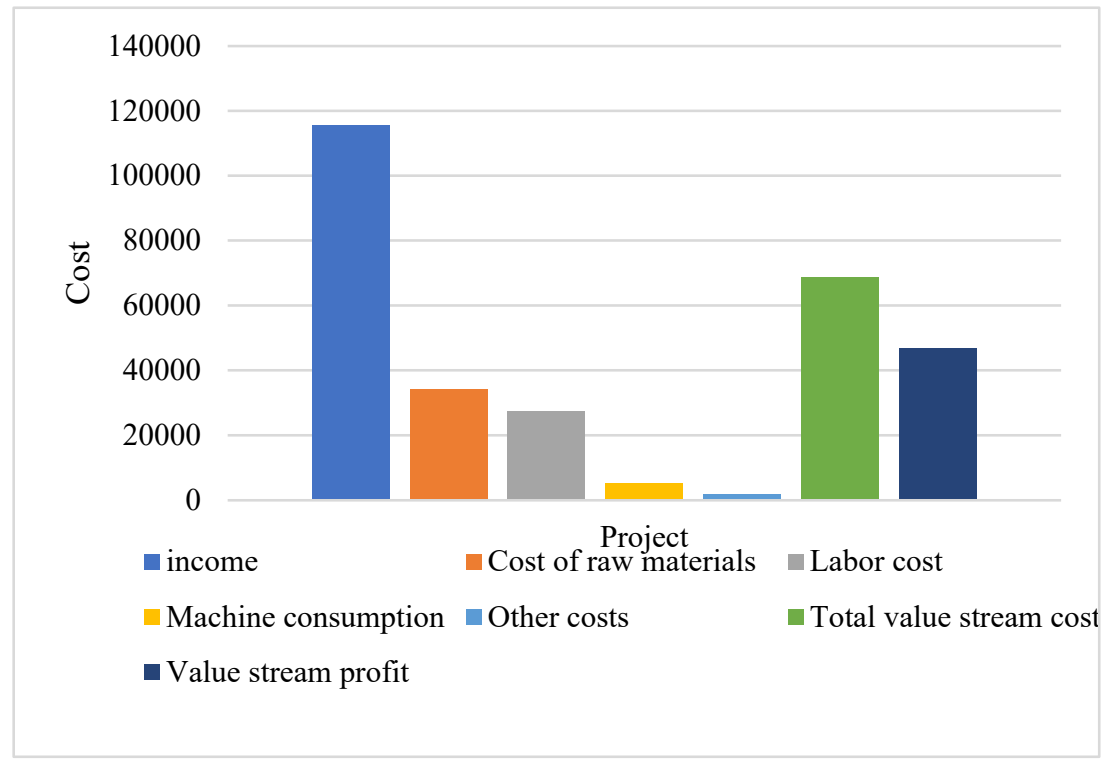

Figure 1. Fluent L corporate value

According to the cost accounting results of value stream, the profit statement of value stream is prepared, as shown in Figure 1. The selling price of roller bearing is 80 yuan / piece, the total income of this week is 115600 yuan, the profit of value stream is 46800 yuan, and the profit rate of value stream is $40.51 \%$.

\subsection{Cost Analysis of Value Stream Based on Lean Management}

Table2. Use of resource capacity for machinery and equipment

\begin{tabular}{|c|c|c|}
\hline Value stream & \multicolumn{2}{|c|}{ Current status } \\
\cline { 2 - 3 } activities & Nonproductive & Productbility \\
\hline $\begin{array}{c}\text { Manufacturing on } \\
\text { demand }\end{array}$ & & 361.25 \\
\hline Plant maintenance & 11 & \\
\hline
\end{tabular}

\begin{tabular}{|c|c|}
\hline $\begin{array}{c}\text { Total time spent on } \\
\text { current status }\end{array}$ & 372.25 \\
\hline $\begin{array}{c}\text { Total unused monthly } \\
\text { time }\end{array}$ & 67.75 \\
\hline $\begin{array}{c}\text { Total time available } \\
\text { per month }\end{array}$ & 440 \\
\hline $\begin{array}{c}\text { Percentage of } \\
\text { productive resource }\end{array}$ & $82.1 \%$ \\
\hline $\begin{array}{c}\text { Percentage of } \\
\text { unproductive } \\
\text { resources }\end{array}$ & $2.5 \%$ \\
\hline $\begin{array}{c}\text { Percentage of } \\
\text { available resources }\end{array}$ & $15.4 \%$ \\
\hline
\end{tabular}

According to table 2, excluding the proportion of productive resources and non productive resources, the available resources of machinery and equipment in the value stream account for $15.40 \%$, which indicates that the resource utilization capacity of machinery and equipment is at a very good level. 
Table3. Use of staff resource capacity

\begin{tabular}{|c|c|c|}
\hline \multirow{2}{*}{$\begin{array}{c}\text { Value stream } \\
\text { activities }\end{array}$} & \multicolumn{2}{|c|}{ Current status } \\
\cline { 2 - 3 } $\begin{array}{c}\text { Manufacturing on } \\
\text { demand }\end{array}$ & Nonproductive & Productbility \\
\hline Dead work & 39.54 & 361.25 \\
\hline $\begin{array}{c}\text { Do poorly done work } \\
\text { over again }\end{array}$ & 142.1 & \\
\hline Handling & 54.14 & 593.99 \\
\hline $\begin{array}{c}\text { Total time spent on } \\
\text { current status }\end{array}$ & \multicolumn{2}{|c|}{46.01} \\
\hline $\begin{array}{c}\text { Total unused monthly } \\
\text { time }\end{array}$ & \multicolumn{2}{|c|}{640} \\
\hline $\begin{array}{c}\text { Total time available } \\
\text { per month }\end{array}$ & $56.45 \%$ \\
\hline $\begin{array}{c}\text { Percentage of } \\
\text { productive resources }\end{array}$ & \multicolumn{2}{|c|}{} \\
\hline \multicolumn{2}{|c|}{}
\end{tabular}

\begin{tabular}{|c|c|}
\hline $\begin{array}{c}\text { Percentage of } \\
\text { unproductive } \\
\text { resources }\end{array}$ & $36.37 \%$ \\
\hline $\begin{array}{c}\text { Percentage of } \\
\text { available resources }\end{array}$ & $7.19 \%$ \\
\hline
\end{tabular}

As can be seen from the above table, although the available resources in the value stream human ability is very low, only $7.19 \%$, indicating that all employees in the value stream are working hard. However, non productive resources accounted for $36.37 \%$, of which the rework time accounted for $61.05 \%$, and the handling time accounted for $23.26 \%$, which seriously affected the value creation ability of enterprises.

\subsection{Compilation and Classification}

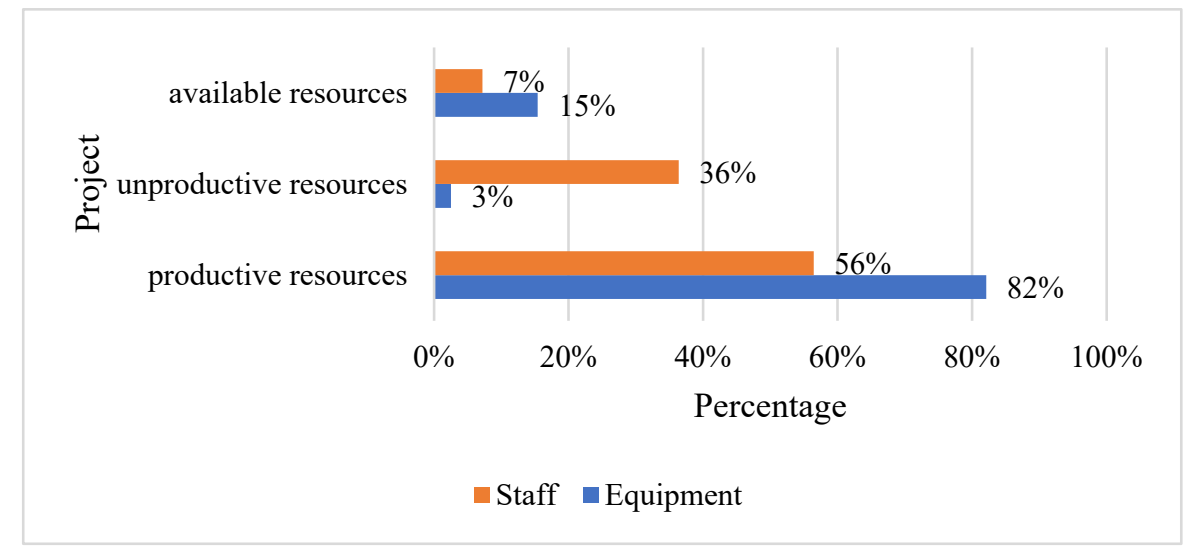

Figure 2. Resource capacity indicators

Table4. Statistical tables

\begin{tabular}{|c|c|c|}
\hline \multicolumn{1}{|c|}{} & Current status \\
\hline \multirow{4}{*}{$\begin{array}{c}\text { Operational } \\
\text { indicators }\end{array}$} & $\begin{array}{c}\text { Per capita } \\
\text { production }\end{array}$ & 5254.55 \\
\cline { 2 - 3 } & Delivery on time & $100 \%$ \\
\cline { 2 - 3 } & $\begin{array}{c}\text { Incoming to } \\
\text { outgoing time }\end{array}$ & 4.64 \\
\cline { 2 - 3 } & First pass & $96 \%$ \\
\cline { 2 - 3 } & Average product & 47.59 \\
\hline \multirow{3}{*}{$\begin{array}{c}\text { Financial } \\
\text { statements }\end{array}$} & Sales income & 115600 \\
\cline { 2 - 3 } & Value stream cost & 68769.79 \\
\cline { 2 - 3 } & Fluent in value & $40.51 \%$ \\
\hline
\end{tabular}

According to the progress analysis chart 2 Table $4,36.37 \%$ of the staff resources are used in non production links, namely handling, rework, preparation, feeding, etc. Therefore, enterprises can reduce the use of labor non productive resources through further lean improvement, and can also avoid adding new labor and increase the cost of value stream.

\subsection{Prediction Under Lean mManagement Mode}

(1) More accurate cost information

Lean cost management is carried out under the premise of standardized operation, which reduces the allocation of indirect costs such as labor costs, makes cost accounting more simple and accurate, and reduces unnecessary cost information tracking. Generally, one week is regarded as a cost reporting cycle, which improves the timeliness of information feedback, helps decision-makers to find cost management problems in time, and improves work efficiency.

(2) Optimize inventory management

Lean inventory management improves the internal production efficiency through Kanban pull system. Establishing long-term strategic cooperation with upstream suppliers, abandoning the strategy of large-scale ordering, and taking small-scale, multi batch and highquality as the indicators of supplier selection can effectively reduce the cost output of warehousing inspection and other processes. To implement "supermarket management mode" for inventory, take "zero inventory" as the management goal, improve the inventory turnover rate, can reduce the increased product cost due to the fluctuation of raw materials.

(3) Effectively eliminate waste and improve economic benefits of enterprises

Lean accounting cost management not only manages the raw materials, manufacturing costs and labor costs of products, but also manages the handling time and product rework in production. Through the classified statistical table, we can see the ability to use human resources and machine resources, so as to better manage the production, 
eliminate unnecessary waste, and improve the economic benefits of enterprises.

(4) Pay more attention to the production process and improve the cost assessment system

The cost management under lean accounting is the management of the whole value stream, but the traditional cost management only manages after production. Value stream includes all processes from order acquisition to after-sales, so value stream cost management includes more cost management links. Traditional cost management usually analyzes the cost information once a month, while lean cost management reflects the cost information once a week, which not only reflects the cost information of products, but also includes a series of value stream performance indicators, such as per capita sales, return rate, on-time delivery rate, first pass rate, etc. Once a week's assessment is also more conducive for managers to understand the operation status and ensure the economic efficiency of enterprises.

\section{Conclusion}

This paper first describes the current situation of enterprise cost management, through specific data to help readers more intuitively understand the enterprise's cost accounting, assessment and analysis methods, convenient for comparison with the lean cost management. The defects of the current cost management method are put forward, and the lean cost management scheme is proposed according to the existing problems. After that, through the value stream cost management of 1 enterprise, using the identification and accounting of value stream cost to obtain more accurate product cost, and through the analysis and assessment, we find all kinds of waste and problems that need to be improved in the production, and put forward specific production management suggestions for the problems. According to the framework of value stream cost management, this paper makes a series of analysis on enterprise cost management, and finally proves that it is feasible to introduce lean accounting cost management into 1 enterprise.

\section{Reference:}

1. Kapanowski G . LEAN ACCOUNTING[J]. Cost management, 2017, 31(1):37-41.

2. Debusk G K . Use Lean Accounting to Add Value to the Organization[J]. Journal of Corporate Accounting \& Finance, 2015, 26(4):29-35.

3. MIKE, DE, LUCA. HOW LEAN ACCOUNTING PROMOTES LEAN IN THE ORGANIZATION[J]. Cost management, 2018, 32(1):21-26.

4. Cokins G . LEAN ACCOUNTING AND ACTIVITYBASED COSTING : A CHOICE OR A BLEND?[J]. Journal of Cost Management, 2019, 33(1):5-15.

5. Collatto D C, Souza M A D, Nascimento A P D, et al. Interactions, convergences and interrelationships between Lean Accounting and Strategic Cost Management: a study in the Lean Production context[J]. Gestão \& Produção, 2016, 23(4):815-827.
6. Drickhamer D . Lean accounting: novel number crunching: a few brave finance and accounting managers are changing how they track costs to support lean manufacturing and improve decision making.(management strategies) $[\mathrm{J}]$. Annals of Cardiothoracic Surgery, 2015, 4(5):463-468.

7. Myrelid A , Olhager J . Hybrid manufacturing accounting in mixed process environments: A methodology and a case study $[\mathrm{J}]$. International Journal of Production Economics, 2019, 210(APR.):137-144.

8. Emeakponuzo D , Eno J , Etim O . Lean Accounting and Waste Management in Brewery Industry in Nigeria[J]. Advances in Research, 2018, 15(1):1-11.

9. Alhosban A A . Effect of Lean Accounting on the Effectiveness of Internal Control in Jordanian Industrial Companies[J]. International Journal of Business and Economics Research, 2019, 8(3):153153 .

10. Iliemena R, Goodluck, Amedu M J . An assessment of the practicability of Lean Accounting in Health care Sector[J]. Test Engineering and Management, 2020, 81(Nov- December 2019):6190-6207. 